\title{
The Phonetic Means of Creating a Ludic Sense in the English Nonsense Text
}

\author{
Irina Anashkina \\ National Research N. P. Ogarev Mordovia State University \\ Correspondence concerning this article should be addressed to Irina Anashkina, National Research \\ N.P. Ogarev Mordovia State University, 68 Bolshevistskaya Str., Saransk, Republic of Mordovia, Russian \\ Federation, 430005.E-mail: iraida952@gmail.com \\ Ekaterina Khramova \\ National Research N. P. Ogarev Mordovia State University

\begin{abstract}
Correspondence concerning this article should be addressed to Ekaterina Khramova, National Research N.P. Ogarev Mordovia State University, 68 Bolshevistskaya Str., Saransk, Republic of Mordovia, Russian Federation, 430005.E-mail: kate_2087@mail.ru
\end{abstract}

\begin{abstract}
Research into the creative use of language can be a source of new knowledge about language structure and its implementation. The paper describes segmental phonetic means involved in the formation of identical or similar acoustic images which interact in the limited semantic space of such English nonsense texts as a limerick and a literary work containing transposed sounds, syllables and words (also known as spoonerisms). This ludic interaction provides the sophisticated plane of expression putting less emphasis on the conveyed message. The analysis included the following stages: 1) identifying the cases of sound-based play in typically English pieces of creative writing; 2) describing the structure and semantics of language units which embody ludic acoustic images; 3 ) looking at the phenomena in question with relation to such constituents of speech act as the message, the addresser and the addressee. The findings reveal that English nonsense texts the plane of expression of which is foregrounded by the creative use of phonetic means demonstrate simultaneous presence and absence of meaning. The results show that dealing with ludic senses allows to appreciate the ludic possibilities of the English phonemic inventory as well as the metalinguistic awareness and literary appreciation of the author and the recipient.
\end{abstract}

Keywords: ludic function of language, ludic sense, ludic mini-text, limerick, spoonerism

Over a long time the phenomenon of language play has been unfairly neglected as a topic for a serious linguistic study. Yet some scholars are aware of the problem and consider it a matter of crucial importance. In particular, they emphasize the following basic ideas: 1) play constitutes an integral part of culture (Huizinga, 1992); 2) language play is not just a characteristic of any speakers regardless of their background and personality but it also indicates the normal development of language skills (Crystal, $2001)$; 3) the phenomenon of language play is equally possible to observe in any language and discourse as well as on any language level (Yagello, 2009). The above-mentioned viewpoints and the extensive literature on language creativity (Barthes, 1989; Lyotard, 1998; Crystal, 2001; Chomsky, 2005; Yagello, 2009) still enable some further research into the ludic function of language, the term applied by David Crystal (2001).

The ludic function of language proves to be closely connected with such communication functions distinguished by Jakobson (1975) as the poetic, the 
emotive and the conative one. This relation can be backed up by the following conditions: 1) the plane of expression foregrounded by the creative use of language (the poetic function $\rightarrow$ the message); 2) the situational character (the emotive function $\rightarrow$ the addresser); 3 ) a challenging linguistic task suggested by the creative author to the recipient who is smart enough to cope with it (the conative function $\rightarrow$ the addressee). On the other hand, the ludic function of language is quite independent due to its peculiarities: it is heuristic (i.e. reveals the possibilities of non-standard use of language) and irrelevant to transmitting information.

Thus, performing the ludic function of language is a metalinguistic activity of the addresser and the addressee. The sender creates a message with a foregrounded plane of expression for the recipient to decipher. These processes result in the formation of a ludic sense in the conceptual systems (as defined by Pavilionis, 1983) of the two speech act participants. The ludic sense can be identified in the limited semantic space of a ludic mini-text. The ludic mini-text is characterised by the creative use of language and may be compared to a kind of a linguistic puzzle meant for the addressee with developed language skills and a broad cultural background.

A limerick and a literary work containing spoonerisms seem to be fine examples of purely English ludic mini-texts the plane of expression of which is to a large extent foregrounded by the creative use of segmental phonetic means. The study of such material can provide some new and useful information on the linguistic creativity of English speakers and the ludic functioning of the English phonemic inventory.

\section{Materials and Methods}

What makes literary nonsense a perfect material for the purposes of this study is its significant relation to language play. Tigges (1988) concludes that devices which constitute a nonsense work "draw attention to the text as an artefact rather than a representation of reality" (pp. 73-74). Nonsense mini-texts are most suggestive of language creativeness. As Tigges (1988) puts it, "a balance between presence and absence of meaning" tends to be better sustained in shorter verse or prose forms (p. 51).

A limerick is commonly defined as a humorous five-line poem with a rhyme scheme aabba (British \& World English Oxford Dictionary (BWEOD), 2016). Among its distinctive features, there is predominantly oral transmission, mass character, comparatively low style, a high degree of variation and repeatability (Bibby, 1978). A limerick can be referred to as a ludic mini-text since its plane of expression prevails over the plane of content which, for the most part, lacks any sense.

According to one of the definitions, a spoonerism is a reversal of sounds in two words, with humorous effects and originates from the name of William Spooner, an English clergyman and scholar of the late 19th and early 20th centuries, who is believed to have accidentally made such slips of the tongue (Hirsch \& Kett, 2002). However, this study looks at intentionally created, crafted spoonerisms which make up one third of the whole literary work and give it nonsensical character.

A text containing spoonerisms is a representative example of a ludic mini-text. Its plane of expression is foregrounded by means of changing the succession of acoustic images. The coherence can be restored by matching mixed sound fragments with corresponding graphic manifestations. Consequently, the task of transmitting information fades away again while a good deal of attention is focused on a clever language manipulation.

Both limericks and spoonerised texts are limited in their length. Limericks conform to the rules imposed on this form of verse (five lines). The length of spoonerised texts does not exceed 800 words because, obviously, a longer piece of such writing would be exhausting to comprehend and its ludic value would inevitably diminish.

It must be noted that the cases of sound-based play discovered in limericks and spoonerised texts can be found in some other pieces of creative English writing representing either poetry or prose. For instance, the interaction of similar or identical acoustic images characteristic of limericks is also contained in various jokes, which are not necessarily poems (Metcalf, 2009). Likewise, it is possible to arrange spoonerisms in such a way they constitute a valid piece of verse (Silverstein, 2005). However, poetic limericks and prosaic spoonerised texts prove to be perfectly appropriate materials for linguistic investigation as they are more specific, diverse and complicated with regard to creative use of the English phonemic inventory and mechanisms for deciphering a ludic sense.

\section{Methodology and Data Collection Tools}

The ludic mini-texts analysed in this study include 168 limericks marked by sound-based play, extracted from the anthology (Rees, 2008) and 43 spoonerised literary works (26 fables and 17 fairy tales). Taking into account a relatively restricted circulation of texts containing spoonerisms, it seems necessary to give some brief information on the sources they are taken from. The fables and fairy tales with transposed sounds, syllables and words were originally created by F. C. Taylor, an American comedian, and compiled 
in the book "My Tale is Twisted! Or the Storal to This Mory" under the pseudonym of Colonel Stoopnagle (James, 2000). The modern version used in the study is an updated revival of that early edition dating back to 1945 . K. James (2000) is convinced that reading such texts aloud as well as listening to them and trying to work out hidden senses contributes to not only stimulating verbal creativity and oral puzzle-solving abilities but also improving social interaction.

The research into the phonetic means of creating a ludic sense in the selected nonsense texts was done in the following stages: 1) identifying the cases of sound play and their quantitative analysis; 2) analysing the structure and semantics of the language units which embody ludic acoustic images; 3) looking at the described phenomena with relation to such constituents of speech act as the message, the addresser and the addressee.

The quantitative analysis includes identifying the most frequent and peripheral cases of soundbased play in the limericks, determining the ratio of really existing lexical units to occasional ones in the spoonerised texts. The structure of the language units embodying ludic acoustic images in the limericks falls into two types: syntagmatic (i. e. visually graspable in a linear sequence) and paradigmatic (i. e. requiring the ability to explicate the correlation between a few acoustic images within the same context). As for the spoonerised texts, the structural analysis means estimating the number of occasional words forming a spoonerism as well as the length and quality of transposed sound fragments. The semantic analysis in relation to the limericks implies dividing the plane of content into two overlapping constituents. In case of the spoonerised texts, it is restoring the coherence.

Producing and reading such mini-texts resembles a linguistic game in which the factor of the addressee takes on a primary importance. Inability to cope with the challenge offered by the addresser and appreciate the creativeness of the message results in disappearance of the ludic effect and absolute pointlessness of the ludic mini-text.

\section{Results and Discussion}

\section{The Phonetic Means of Creating a Ludic Sense in the Limerick Nonsense Text}

According to the results of the analysis, soundbased play in the limericks is almost equally presented in two major ways: exploiting the language sign asymmetry and likening the graphic manifestations of rhyming words. The comparatively vast amount of the limericks demonstrates imitation of pronunciation mistakes and foreign accents. The frequency of the above-mentioned cases and diverse peripheral ones may be presented as follows in Table 1:

Table 1

The frequency of sound-based play cases in the limerick nonsense text

\begin{tabular}{|c|c|}
\hline The cases of sound-based play & $\begin{array}{l}\text { The number of } \\
\text { mini-texts }\end{array}$ \\
\hline Exploiting the language sign asymmetry & 57 \\
\hline $\begin{array}{l}\text { Likening the graphic manifestations of rhym- } \\
\text { ing words }\end{array}$ & 50 \\
\hline $\begin{array}{l}\text { Imitation of pronunciation mistakes and } \\
\text { foreign accents }\end{array}$ & 22 \\
\hline $\begin{array}{l}\text { Keeping the rhythm by means of occasional } \\
\text { or unexpected lexical units or violating the } \\
\text { rhythm }\end{array}$ & 10 \\
\hline Onomatopoeia & 8 \\
\hline Shifting word boundaries & 7 \\
\hline Paronymic attraction & 5 \\
\hline Phonaesthemic clusters & 5 \\
\hline Reduplication & 4 \\
\hline Shortening graphic manifestations & 3 \\
\hline
\end{tabular}

Figure 1 shows the proportion of each case. This paper will consider in detail only the ones that are the most frequent, representative and, therefore, the most characteristic of limericks.

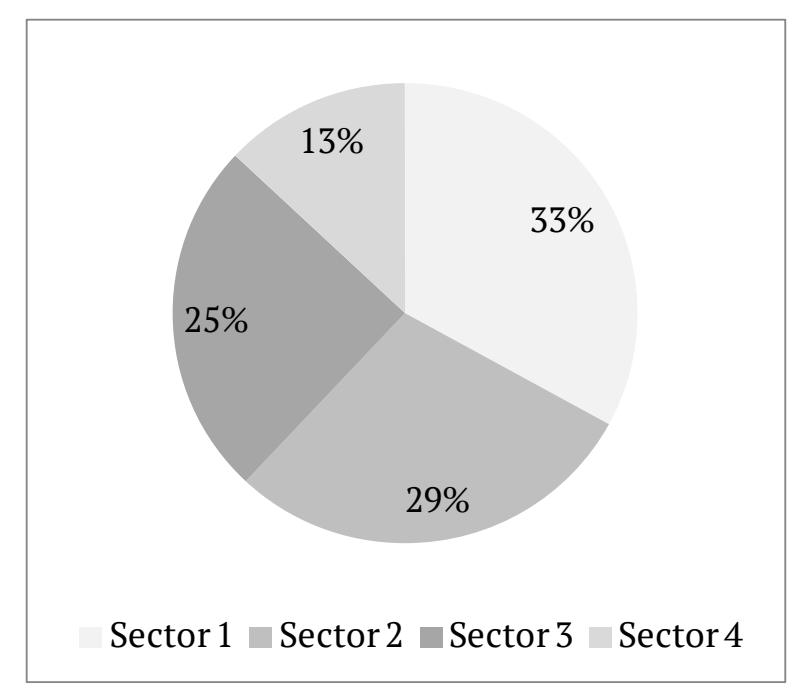

Figure 1. The proportion of sound-based play cases in the limerick nonsense text.

Sector 1 (33\%) Exploiting the language sign asym metry.

Sector 2 (29\%) Likening the graphic manifestations of rhyming words.

Sector 3 (25\%) Peripheral cases of sound-based play. Sector $4(13 \%)$ Imitation of pronunciation mistakes and foreign accents. 


\section{Exploiting the Language Sign Asymmetry}

The language sign asymmetry is the natural absence of a balance between the signifier and the signified (Saussure, 1999). In the analysed limericks of this kind the plane of the content is intentionally doubled by means of such lexical units embodying identical acoustic images, either of syntagmatic or paradigmatic structure that express two different meanings at a time. These cases are found in 66 limericks and are comprised of homophones (42\%), polysemantic units (37\%), and homonyms proper (21\%). In order to comprehend the ludic mini-text, the recipient has to do a metalinguistic activity of selecting and comparing lexical units whose graphic manifestations, either identical (polysemantic units, homonyms proper) or different (homophones) convey precisely the same acoustic images.

The syntagmatic structure of language units embodying identical acoustic images may be observed in this piece of black nonsensical humour:

At the railway station, old Jim

Crossed over the line on a whim;

When he crossed back again,

He did not miss his train,

And the train, sadly, didn't miss him!

(Rees, 2008, p. 443)

The polysemantic verb miss [mis] (Jones, 2011, p. 320 ) is mentioned twice and each time it expresses a different meaning depending on the agent and the object of the action. On the one hand, the word means "be too late to catch a passenger vehicle" and implies an animate agent (a person) and an inanimate object (a vehicle). On the other hand, miss denotes "fail to hit, reach" and gives an idea of the train as an agent and poor old Jim as an object (BWEOD, 2016).

The paradigmatic structure of language units embodying identical acoustic images seems to provide a more sophisticated case of sound-based play as below:

\section{A dentist who lives in Duluth \\ Has wedded a widow named Ruth; \\ She is so sentimental \\ Concerning things dental, \\ She calls her dear second her twoth (Rees, 2008, p. 82).}

While listening to this limerick the recipient is supposed to associate the last word with the acoustic image [tu: $\theta$ ] which is known to correspond with the graphic manifestation "tooth" (Jones, 2011, p. 497). However, the written text contains the occasional unit twoth suggestive of English ordinal numerals. Such a mistake allows the reader to presume that the described widow is an illiterate woman using twoth instead of required second. Simultaneously, another plane of the content conjures up a weird manner of calling the husband who works as a dentist "my tooth".

A balance between presence and absence of meaning within one limerick can be achieved through a great many sources of a ludic sense:
A fly and a flea in a flue
Were imprisoned, but what could they do?
Said the fly: "Let us flee!"
Said the flea: "Let us fly!"
And they flew through a flaw in the flue
(Rees, 2008, p. 56).

This limerick demonstrates a fairly complex interaction of identical acoustic images: 1) homonyms proper: fly [flas] (a flying insect of a large order characterised by a single pair of transparent wings and sucking mouthparts) and fly [flar] (move through the air using wings) (Jones, 2011, p. 192; BWEOD, 2016); 2) homophones: flea [fli:] (a small wingless jumping insect which feeds on the blood of mammals and birds) and flee [fli:] (run away from a place or a situation of danger) (Jones, 2011, p. 190; BWEOD, 2016); 3) homophones: flue [flu:] (a duct for smoke and waste gases produced by a fire, a gas heater, a power station, or other fuel-burning installation) and flew [flu:] (past of fly) (Jones, 2011, pp. 190-191; BWEOD, 2016). Being barely comprehensible in a written form the text is expected to become more difficult to understand when listened to. Furthermore, reading the limerick aloud reminds us of practising a tongue-twister, which is aimed at mastering the articulation of certain sounds but not delivering any message.

Thus, a clash between two planes of the content in a limerick is often provoked by the ludic interaction of identical acoustic images conveying different meanings. The lexical units which embody these images can be presented both explicitly (syntagmatically) and implicitly (paradigmatically). A balance between presence and absence of meaning characteristic of nonsense texts is especially evident when the sources of a ludic sense are exceedingly numerous.

\section{Likening the Graphic Manifestations of Rhyming Words}

While appreciating the ludic effect of exploiting the language sign asymmetry is usually associated with an aural perception of the text, likening the graphic manifestations of rhyming words is an exclusively visual verbal art. The possibility of such a peculiar and, at the same time, a characteristic way of performing the ludic language function in the limerick nonsense text can be explained by the following reasons: 1) a definite rhyme scheme (rhyme aabba; three feet in the 1st, 2nd and 5th lines; two feet in the 3rd and 4th lines) (Bibby, 1978, p. 26); 2) a structured plane of the content (introducing a character or situation in the 1st and 2nd lines; performing an action in the 3rd and 
4th lines; drawing a conclusion in the 5th line) (Bibby, 1978, p. 26); 3) and different graphic manifestations of identical acoustic images in the English language.

This case of sound-based play consists in partial reproducing the graphic manifestations of one word (as a rule, the last word of the 1st line) by other rhyming ones. It leads to coining occasional units that produce the nonsensical effect and make it difficult to comprehend the written text. The addressee has to solve the linguistic challenge of correlating these coinages with really existing spellings.

In this study, the real words (one or two) whose graphic manifestation is reproduced (often rare proper names with complicated spellings) are called the leading components. The occasional units (from one to three) resulting from such reproduction are named the derived components. As a result of the analysis, the following basic formula was worked out: $\mathrm{A} x \mathrm{AyB} x \mathrm{ByB} z$, where $\mathrm{A}$ - the leading component, $\mathrm{B}$ - the derived component, $x, y, z$ - the numbers of the lines in the limerick. The most frequent formula is A1B2B5 (70\%). It can be illustrated by the example:

\section{There was a young fellow of Beaulieu}

Who loved a fair maiden most treaulieu;

He said: "Do be mine".

And she didn't decline,

So the wedding was solemnized deaulieu

(Rees, 2008, p. 244).

In this limerick, the leading component is the geographical name Beaulieu which denotes a village in the English county of Hampshire. The derived components are treaulieu and deaulieu. In order to decipher the occasional units in the second and the fifth lines it is necessary to know the pronunciation of the leading component. The acoustic image ['bju:.li], recorded in the dictionary (Jones, 2011, p. 48), makes the addressee come up with such rhyming items as ['tru:.li] and ['dju:.li]. The next step is to identify the real graphic manifestations of these units which turn out to be truly and duly (Jones, 2011, pp. 152, 505).

Other possible formulas include A1A2B5 (6\%), A1B2C3D4B5 (6\%), A1B5 (4\%), A1B2 (2\%), A2B5 (2\%), A3B4 (2\%), A1B5B5 (2\%), A1B2D3C4B5 (2\%), A1B2B5B5 (2\%), A1B1B2B5 (2\%). The most representative ways of variation in structure are as follows: 1) there may be only one occasional derivative which ends any rhyming line of the limerick; 2) there may be two leading components each of which can correlate with its own dependant derivative; 3 ) one line may contain two occasional units.

So, likening the graphic manifestations of rhyming words is a characteristic of limericks only. A balance between presence and absence of meaning is attained when the mini-text is perceived visually and successfully deciphered thanks to the recipient's knowledge of English vocabulary. The text with such visual rhyme becomes an artefact the communicative value of which is less important than the creative manipulation of the difference between spelling and pronunciation.

\section{Summing Up}

The results of analysing the phonetic means of creating a ludic sense in the limerick nonsense text allow to draw some generalisations.

- The form of this verse makes it possible to apply unconventional ways of sound-based play connected with the rhythm and rhyme peculiarities.

- The wide variation in the graphic manifestation of acoustic images in the English language is exploited by means of coining visual rhymes.

- A ludic sense is conveyed through a different number of words which often include nonexisting occasional ones.

- The plane of the content is doubled due to the correlation between meanings expressed by the following pairs of lexical units: 1) those with identical or similar acoustic images; 2) those with identical or similar graphic manifestations; 3) those imitating pronunciation mistakes or accents and representing correct pronunciation.

- A balance between presence and absence of meaning is maintained owing to: 1) simultaneous expression of several meanings, one of which seems to be natural in the given context and another one conjures up an absurd picture; 2) different emphasis on perceiving a limerick: in an aural or written form; 3) distorted lexical units imitating false pronunciation and key words helping identify the reason for such deviations.

- Aural presentation of a limerick is essential for producing the ludic effect when the text is saturated with lexical units embodying identical or similar acoustic images.

- The written presentation of a limerick is important when the emphasis is placed on either shortened graphic manifestations or spelling coinages conveying rhyming acoustic images.

\section{The Phonetic Means of Creating a Ludic Sense in the Spoonerised Nonsense Text}

The analysis of the spoonerised literary works shows that spoonerisms make up one third of the whole text and vary in structure. 
The book Stoopnagle's Tale Is Twisted: Spoonerisms Run Amok contains 26 fables the average length of which includes 214 words, and 17 tales, which, on average, include 579 words. Spoonerisms make up 34$35 \%$ of the whole text.

The spoonerisms in this book are complicated and, at the same time, successfully represent language play of exactly phonetic character. Their main features are as follows: 1) sound transposition affects not only initial, but also middle and final fragments, which may be sounds, sound complexes or even acoustic images embraced by the whole words; 2) spoonerisms are made of not only consonants, but also vowels; 3 ) if necessary, spellings are adapted to provide adequate performing according to the reading rules; 4) sometimes a fragment to be transposed is made recognisable with a hyphen; 5) sound transposition may involve from one to three words.

The table below illustrates the spoonerised fable and its deciphered version.

Table 2

Restoring the coherence of the spoonerised fable

\begin{tabular}{cc}
\hline Spoonerised Text & Deciphered Text \\
\hline The Loose That Gaid & The Goose That Laid \\
the Olden Geggs & the Golden Eggs
\end{tabular}

Back in the not too pastant dist, Back in the not too distant past, a carried mouple was nortunate a married couple was fortunate efough to possoose a gess that enough to possess a goose that laid an olden gegg every dingle laid a golden egg every single say of the week.

This they considered a great loke of struck, but, like some other neople we po, they thought they weren't getting fitch rast enough.

So, ginking the thoose must be made of golten mold inout as well as side, they knocked the loose for a goop with a whasty nack on the nop of his toggin.

Goor little poose!

Anyway, they expected to set at the gourse of all this mecious prettal.

But as huck would lav it, the ingides of the soose were just like the ingides of any other soose. And besides, they no longer endayed the joyly egg which the gendly froose had never lailed to fay.

And the storal to this mory is:

Wark the murds of mize wen: "All that glitts is not golder» (James, 2000, pp. 7-8). day of the week.

This they considered a great stroke of luck, but, like some other people we know, they thought they weren't getting rich fast enough.

So, thinking the goose must be made of molten gold inside as well as out, they knocked the goose for a loop with a nasty whack on the top of his noggin. Poor little goose!

Anyway, they expected to get at the source of all this precious metal.

But as luck would have it, the insides of the goose were just like the insides of any other goose.

And besides, they no longer enjoyed the daily egg which the friendly goose had never failed to lay.

And the moral to this story is: Mark the words of wise men: «All that glitters is not gold

The fable The Loose That Gaid the Olden Geggs (The
Goose That Laid the Golden Eggs) incorporates 37\% of spoonerisms. It seems to be enough to point out only those cases of sound transposition that reflect the peculiarities of phonetic spoonerisms. First, the noninitial sounds are transposed: nortunate ['no:tfonət]

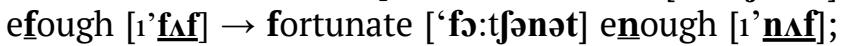
the ingides [1n'gardz] of the soose [su:s] $\rightarrow$ the insides [1n'saidz] of the goose [gu:s]. Second, the vowels are switched: all that glitts [glits] is not golder ['gəolda] $\rightarrow$ all that glitters ['glitąz] is not gold [gəold]. Third, the spoonerisms imply transposition of acoustic images embodied by sound complexes, syllables, morphemes, words: pastant ['pa:stənt] dist [dist] $\rightarrow$ distant ['distənt] past [pa:st]; to possoose [pə'zu:s] a gess [ges] $\rightarrow$ to possess [po'zes] a goose [gu:s]; inout [1n'avt] as well as side [said] $\rightarrow$ inside [1n'said] as well as out [avt].

Finally, special consideration must be given to the ways of adapting the graphic manifestations:

other neople ['ni:pl] we po [pəv] $\rightarrow$ other people ['pi:pl] we know [nəo] (pow would sound as [pao] (Jones, 2011, p. 389));

getting fitch [fit [] rast [ra:st] enough $\rightarrow$ getting rich [ritf] fast [fa:st] enough (compare: fiche [fi:f] (Jones, 2011, p. 186));

mecious ['mefəs] prettal ['pretəl] $\rightarrow$ precious ['prefəs] metal ['metəl] (double 't' closes the syllable and makes 'e' sound as [e] but not [i:]);

as huck [hık] would lav [læev] it $\rightarrow$ as luck [l/kk] would have [hæv] it (deleting 'e', which opens the syllable, provides the required pronunciation; compare: lave [leiv] (Jones, 2011, p. 285));

endayed [1n'deid] the joyly ['dzoll1] egg $\rightarrow$ enjoyed [1n'dzold] the daily ['delli] egg ('ay' seems to be more natural before 'ed'; cp.: played [ple1d] (Jones, 2011, p. 382));

gendly ['gendlı] froose [fru:s] $\rightarrow$ friendly ['frendlı] goose [gu:s] (deleting ' $\mathrm{i}$ ' makes it impossible to pronounce [i:]; compare: lief [li:f] (Jones, 2011, p. 289)); wark [wa:k] the murds [m3:dz] $\rightarrow$ mark [ma:k] the words [w3:dz] ('ur' usually sounds as [3:], unlike 'or', which is pronounced in this way after ' $w$ '); mize [maiz] wen [wen] $\rightarrow$ wise [walz] men [men].

The sound-based play represented by spoonerised fables and tales makes an impression of a highly sophisticated and complicated verbal art. Comprehending this ludic mini-text most of all resembles solving a linguistic puzzle. It can be a challenge for only one reader who tries to write the deciphered version as well as two recipients, one of whom has to read the text following the reading rules and the other one has to restore the coherence of the passage in their mind. Such a task requires developed language skills and contributes to better language acquisition. 


\section{Conclusion}

The analysis of the spoonerised literary works reveals the addresser's advanced level of language creativity. Consequently, the potential addressee has to match the same requirements to appreciate such a verbal artefact. Reading spoonerised texts means solving the problem of restoring the coherence by appropriately shifting the intentionally mixed acoustic images. The ludic effect becomes more profound when these pieces of creative writing are read aloud and perceived aurally: this metalinguistic activity improves not only the command of English but also the social interaction between the reader and the listener who act as participants of a language game. A balance of presence and absence of meaning is sustained in the following way: on the one hand, a text which incorporates approximately $30 \%$ of spoonerisms is a meaningless message; on the other hand, the recipient who is competent enough to decipher its plane of

expression can get the hidden information.

Limericks and spoonerised literary works can be considered typically English examples of ludic minitexts the plane of expression of which is foregrounded by the creative use of the phonemic inventory.

The analysis carried out makes it possible to point out the most representative cases of sound-based play: 1) exploiting the language sign asymmetry which results in interacting two identical acoustic images embodied by polysemantic words, homonyms proper or homophones; 2) unconventional phonetic means of creating a ludic sense suggested by the rhythm and rhyme of limericks (especially likening the graphic manifestations of rhyming words); 3) visual rhyme and phonetic spoonerisms based on exploiting the differences and difficulties in spelling acoustic images; 4) numerous occasional units which make sense only being engaged in sound-based play.

The challenge offered by the creative addresser to the addressee who is competent enough at linguistics in general and English in particular consists in distinguishing and comparing two planes of content emerging as a result of sound-based play. Thus, such a piece of writing becomes a valid text only on condition that its language creativeness is successfully comprehended and properly appreciated.

Limericks are characterised by either syntagmatic or paradigmatic organisation of lexical units which convey a ludic sense while spoonerised texts demonstrate exclusively linear presentation of interacting acoustic images. The ludic effect which occurs as a consequence of deciphering the plane of expression is caused by simultaneous presence and absence of meaning. Such a clash can be both amusing (as in most limericks) and suggestive of a bizarre linguistic word puzzle (as in spoonerised texts).

Thus, literary and teaching value of nonsense texts is linguistic in nature because it does not imply the evaluation of ideas but rather deals with decoding the message by means of clever language manipulations. These samples of verbal art can be useful as a teaching material for developing learners' cognitive language skills: the ability to observe the relations between language units and consider them to be elements of the system. Nonsense texts are also culturally significant as they represent a typically English trend in literature.

Further research into the phonetic means of creating a ludic sense in the limited semantic space can include the comparative analysis of different English mini-texts (e.g. jokes, tongue-twisters, rhyming slang etc.) and the study of suprasegmental features like stress and pitch.

\section{References}

Barthes, R. (1989). Udovol'stvie ot teksta [Pleasure from the text]. In G. K. Kosikov (Ed.), Barthes $R$. Izbrannye raboty: Semiotika. Poetika (pp. 462-518). Moscow, USSR: Progress.

Bibby, C. (1978). The art of the limerick. London, UK: Research Publishing Co.

British \& world English Oxford dictionary. (2016). Oxford University Press. Retrieved from http:// www.oxforddictionaries.com/

Chomsky, N. (2005). Kartezianskaya lingvistika. Glava iz istorii ratsionalisticheskoi mysli [Cartesian linguistics. A chapter from the history of rationalist thought]. Moscow, Russia: Komkniga.

Crystal, D. (2001). Language play. Chicago, IL: The University of Chicago Press.

de Saussure, F. (1999). Kurs obshchei lingvistiki [The course in general linguistics]. Yekaterinburg: The Ural University Publishing.

Hirsch, E. D., \& Kett, J. F. (2002). The new dictionary of cultural literacy. New York, NY: Houghton Mifflin Harcourt.

Huizinga, J. (1992). Homo ludens. V teni zavtrashnego dnya [Homo ludens. In the shadow of tomorrow]. Moscow, Russia: Progress.

Jakobson, R. (1975). Lingvistika i poetika [Linguistics and poetics]. In E. Y. Basin \& M. Y. Polyakov (Eds.), Strukturalizm: “Za” i "protiv" (pp. 193-230). Moscow, USSR: Progress.

James, K. (2000). Stoopnagle's tale is twisted: Spoonerisms run amok. Sherman Oaks, CA: Stone and Scott Publishers.

Jones, D. (2011). Cambridge English pronouncing 
dictionary. Cambridge, UK: Cambridge University Press.

Lyotard, J.-F. (1998). Sostoyanie postmoderna [State of postmodernism]. Moscow, Russia: Aleteya.

Metcalf, F. (2009). The penguin dictionary of jokes, wisecracks, quips and quotes. London, UK: Penguin Books.

Pavilionis, R. (1983). Problema smysla. Sovremennyi logiko-filosofskii analiz yazyka [The problem of meaning. The modern logical and philosophical analysis of language]. Moscow, USSR: Mysl’.
Rees, G. (2008). The mammoth book of limericks. London, UK: Running Press.

Silverstein, Sh. (2005). Runny babbit: A Billy Sook. New York, NY: Harper Collins Publishers.

Tigges, W. (1988). An anatomy of literary nonsense. Amsterdam, Netherlands: Rodopi.

Yagello, M. (2009). Alisa v Strane Yazyka. Tem, kto khochet ponyat' lingvistiku [Alice in Language Land. To those who wants to understand linguistics]. Moscow, Russia: Librokom. 